\title{
Unleashing the Creativity of Entrepreneurs with Digital Technologies
}

\author{
Robert D. Hisrich and Mariusz Soltanifar
}

\section{Abstract}

For decades, creativity has been used to generate ideas among entrepreneurs and their teams. Although extensive research has been conducted on creativity, the majority of studies have focused on traditional ways of stimulating creativity, such as focus groups, the collective notebook method, brainstorming, brainwriting, reverse brainstorming and problem inventory analysis. However, the digital age appears to challenge much of this existing work on the nature of creativity. It is clear that online creativity and audiences are affecting the meaning, expression and impact of creativity. The traditional techniques of stimulating creativity have been replaced and aided by technology-driven innovations, such as artificial intelligence (AI), virtual reality (VR) and the Internet of things (IoT). This chapter explores ways to activate the creativity of entrepreneurs and their teams through the use of digital technologies. We believe that this chapter provides a rich source of examples on how technology is currently being used to support creativity by encouraging entrepreneurs and their teams to make connections, develop ideas, create meaning, collaborate and communicate. We present, in detail, three case studies and discuss practical implications for the future.

\footnotetext{
R. D. Hisrich ( $\bowtie)$

Kent State University, Ohio, USA

e-mail: rhisrich1@kent.edu

M. Soltanifar

Hanze University of Applied Sciences, Groningen, The Netherlands
}

M. Soltanifar

Open University, Heerlen, The Netherlands 


\section{Introduction}

One could argue that what ultimately distinguishes humans from other species on this planet is our creativity. It has given us the unique ability to shape our own destiny, whether for good or bad. Creativity has enabled us to shape the present, recreate what came before us and build the future that we envision for ourselves. As a species, we can visualise things that do not exist, allowing us to bring them to life, changing the world. For example, for some time, various creativity techniques, such as free association, forced relationships and attribute listing, and parameter analysis, have been used as ways to generate ideas among entrepreneurs and their teams. Today's organisations operate in an increasingly competitive and globalised environment, making creativity a crucial part of organisations (Amabile and Khaire 2008; Landry 2017). In addition, this competitive and globalised environment has now become digitised.

Pervasive digitisation is not only opening a new window of opportunity but also changes the way in which ideas are generated and how creative tools are applied. Creativity fuels big ideas and opens the door for new opportunities while challenging employees to think creatively by tapping into their creative outputs. Through accommodating the creative ideas of employees, the company can continually innovate its products and services to sustain a competitive advantage (Soltanifar 2016). The importance of creativity has grown throughout the years, with companies focusing on it more each year. For instance, based on IBM's survey of more than 1500 chief executive officers, creativity has been ranked as the number one factor for future business success (Landry 2017). A 2018 Deloitte survey of 500 companies - each with revenues somewhere between \$100 million USD and over $\$ 1$ billion annually - found that approximately $57 \%$ of companies of this size plan on spending even more on tech in the years ahead than they have in the past (Deloitte 2018).

Although creativity has been present in research and practice for many years (Gabora 2013), resulting in extensive research on creativity (British Council 2020; Said-Metwaly et al. 2017; Banaji 2010), the majority of studies still focus on the traditional ways of stimulating creativity, as mentioned above. Creativity, as such, has not changed much, though its surrounding landscape has changed dramatically through the increasingly digitised business environment (Johnson 2016). Traditional techniques of stimulating creativity have been replaced and enhanced by technology-driven tools, such as virtual rooms, decision cockpits, various communication tools and interactive dashboards. In particular, the Internet of things (IoT), artificial intelligence (AI) and virtual reality (VR) have an impact on the creativity of entrepreneurs and their teams, which is the focus of this chapter. These tools can enhance creative processes. For example, AI can be used to uncover certain statistics and help determine marketing opportunities, which can be more efficient and diverse compared with traditional practices. Furthermore, the use of the IoT has now made it possible for ideas to be sourced from virtually anywhere, going beyond the capabilities of manpower. This impact is seen in the hiring of 
more creative-minded individuals, the incorporation of design thinking, particularly in the area of new products and services, the design of new packages that are not only recyclable but also can be used for other purposes, more expressive and meaningful social media messaging, and incorporating a thinking-outside-the-box mentality when addressing various marketing problems.

The sourcing of ideas is now more than ever being influenced by larger changes in interactions between people, communities, creative processes, knowledge domains and wider social contexts. As there is a sizeable research gap in linking the digital environment to creativity, the aim of this chapter is to understand how entrepreneurs and their teams can use digital technologies to support creativity. Based on this, our research question for this chapter is: How can we support the creativity of entrepreneurs and their teams using digital technologies, and in particular, how can we do this through artificial intelligence, virtual reality and the Internet of things?

By reviewing recent literature on creativity and discussing three practical cases, we link creativity to digital business and highlight the importance of creativity for digital businesses. More specifically, we position creativity as a way of stimulating entrepreneurial behaviour, using creativity as a basis for innovation and creating a working environment where ideas can flourish. We also investigate how entrepreneurs and their teams can utilise digital technologies to support creativity. In this chapter, we examine how entrepreneurs can harness digital technologies to ignite creativity, power human enterprise and support creativity among themselves and their teams. We contribute to the literature on creativity and entrepreneurship in three major ways. First, this paper expands our understanding of creativity by adding a new dimension of creativity stimulated by digital technology. Second, we emphasise the need for positioning companies into a digital business environment landscape that encourages the application of digital tools to support creativity. Third, we shed light on managerial practices and deliver practical implications to corporate executives and managers and individual entrepreneurs and their teams.

\section{Conceptualising Creativity in Digital Business}

Artistic expression, co-creation and the dissemination of business ideas are now more common than ever before, being transformed through rapidly evolving digital technologies (Gardner and Weinstein 2018). In the field of artistic expression, lines are also being blurred with the advent of these digital technologies, as audience engagement takes on a whole new meaning in which communication with the audience and performance intertwine and, occasionally, become one. For instance, the affinity groups are a great example of co-creation, as they allow individuals with similar interests to mentor and support each other in the development of their creative skills. Sites such as Behance, DevianArt and Dribble allow professional artists and designers to share their work and receive constructive feedback and inspiration. Both feedback and inspiration may lead to business ideas and 
improvements. Social networking services (SNSs) have also had a major impact on creativity and the creation thereof. It has become especially apparent how large their impact has been and will continue to be when looking at the unprecedented and seemingly endless number of interactions taking place on these networks.

With digital technologies, the possibilities for individuals to express themselves in exactly the way that they see fit have become nearly infinite. Individuals can now express themselves and showcase their talents without bounds and may connect with audiences that have similar interests. This phenomenon becomes very evident on platforms such as Medium, Instagram and YouTube. All three platforms allow for future professionals, artists and amateurs to post content on these platforms and test the market for future business endeavours. An interesting perspective to consider is that when millions of photos are taken and uploaded to Instagram, there are bound to be great creative shots as a result. The same could be assumed for the 500 million tweets posted daily. The probability for great content and creativeness rises with frequency (Chamorro-Premuzic 2015).

Before we present various ways to foster creativity by making use of digital technologies, we will define creativity and elaborate on the importance of creativity for digital businesses.

\subsection{Defining Creativity}

Over the years, the process of defining creativity has led to the development of various perspectives. The areas of cognition, personality and the stimulation of creativity in people were the main focus of defining creativity in the 1950s to 1970 s (Mehta and Dahl 2019). Later, in the 1980s and 1990s, that focus shifted to the influence of environments and the social context of the creativity of individuals. In 2005, Cropley reviewed numerous attempts to classify creativity. One of the more notable attempts was of Joy Paul Guilford, American psychologist, stressing the importance of 'divergent' thinking in human psychology, noting the role of creativity in successful technological and economic ventures. Guilford settled on three elements of the variety of discussions about creativity: novelty, effectiveness and ethicality, and focused on people that demonstrated these characteristics and interacted with others while in a 'creativity-friendly' environment (Loveless 2002).

Several reviews exist that help to define and theorise the nature of creativity. Dust's (1999) review provides recommendations for achieving the goals of exploration, exploitation and explanation to achieve the main objective: the promotion of talent, innovativeness and creativity in the fields of science, technology and art. However, it is important to note that much of the work cited in various literature has been undertaken in the USA, UK and Europe, meaning we must acknowledge the possibility of 'cultural saturation' in Western concepts of creativity, as it might lead to limitations in understanding the creativity of other cultures. A key point in defining creativity is whether to focus on unique and one-of-a-kind creative individuals, such as Albert Einstein or Charlie Parker, who possess paradigm-shifting abilities in society's way of knowing, or to focus on any 
and all individuals and the normal person's ability and potential for selfactualisation. For our paper, the focus is broad, as we aim to find ways to stimulate creativity in employees/intrapreneurs.

Creativity can be defined in different ways, and truthfully, everyone has their own understanding of the concept. Creativity in business can be defined as an act that generates or makes use of a new idea and requires a different approach to the problem. This is the sole definition that can be projected onto any person who is labelled 'creative'. This definition is, however, quite broad, and it might help to investigate some definitions which dive below the surface. According to Naiman, the founder of Creativity Work and a mentor in creative output, creativity can be summed up as the ability to tap into our 'inner' pool of resources-knowledge, insight, information, inspiration and all the fragments populating our minds. Thus, it is not only the forming of ideas but also our ability to access them and put them to use. While these two definitions are different, they both place creativity into one category, which can be summarised as a complex process of the creation of ideas and the further development of these ideas. Whether it is an artist writing a song, or an employee at a company meeting during a brainstorming session, these individuals attain an idea and try to make it into something tangible. Creativity can be regarded as not only a quality found in exceptional individuals but also as an essential life skill through which any employee can develop their potential to use their imagination to express themselves and make original and valued choices in their lives. This is enhanced through an evergreen termed 'the artist way', which assists individuals in entrepreneurship and digital marketing to become more creative.

In this chapter, we refer to creativity as the ability of an individual, or a small group of individuals, to generate novel and useful ideas to take advantage of the new opportunities offered by digital technologies. Creativity, a process that can result in incremental improvements, is the core of innovation and necessary for the development of new business concepts. While there are numerous perspectives (psychological, social, individual, economic and organisational), creativity is the application of an individuals' ability to identify and develop new ideas, processes or concepts in novel ways. These new ideas, processes or concepts must be useful and have value or meaning. For instance, Netflix is a creative company that recognised an opportunity and capitalised on the success of the DVD and Internet streaming services. Netflix overcame a series of hurdles to launch and become a $\$ 9$ billion company. Creativity leads to perseverance, passion and commitment, which can be seen from companies such as Apple, Amazon, Facebook, Google, Salesforce.com, Samsung, Twitter, Virgin Atlantic and 3M. Digital technology implies a broad range of information and communications technologies (including new digital media) that can be used for different purposes by entrepreneurs in many situations. Next, we elaborate on the importance of creativity for stimulating entrepreneurial behaviour, using creativity as a basis for innovation, and creating a working environment where ideas can flourish. 


\subsection{The Importance of Creativity for Digital Entrepreneurship}

Creativity brings numerous benefits to entrepreneurs and their teams. One of the major benefits of creativity is to stimulate entrepreneurial behaviour, and in particular, innovativeness, proactiveness and risk-taking (Kuratko and Morris 2018). Therefore, it is worthwhile to explore the effects of digital technologies on creativity in an entrepreneurial context. There are many attributes that fall under entrepreneurial behaviour, but perhaps one of the most important ones is the need and want for change, or in other words, innovation. Innovation is an inevitable aspect of the business world, as without it there would be no progress. Creativity and innovation are two terms that go hand in hand from an entrepreneurial perspective. Judging by the creativity types explained above, you may find that creativity is not just a state of mind but also the work, training and the will to create something of worth for yourself and others. Entrepreneurs are drivers of change and are persistent in perfecting the techniques and skills in their given field.

'A composer must use the piano to test a song he is creating, but, if he does not know the piano execution techniques well, his mind will be absorbed by choice of the correct notes, and it will distract him from his composition' (Kamel et al. 2017, p. 5).

In thinking about the above quote, we may gather that entrepreneurs work on perfecting their techniques to pave the way for new ideas they want to implement.

A good example of an entrepreneur taking their knowledge of the industry and creating a new, digitally creative business idea is Chinese entrepreneur Jenny Zhiya Qian, who co-founded Luckin Coffee in October 2017. Knowing the Chinese market and their habits, the company stepped away from traditional coffee shop tactics and has opted for selling their products through a delivery service rather than at a brick-and-mortar location. Through creative digital innovation, Luckin Coffee has become one of the fastest-growing start-ups, with the average total items sold that increased $470.1 \%$ from 7.8 million in the third quarter of 2018 to 44.2 million during the recent quarter. Revenue was strong, with total net revenue of \$215.7 million USD (Cardwell 2020). Without creativity, there are no innovative solutions/ideas. Creativity, in its most basic form, is about idea generation, innovation and the implementation of ideas (Gilson and Litchfield 2017). Digital technologies play a crucial role in facilitating meaningful, collaborative activity. Such collaborative activity refers to any project that involves building something together through a process of co-creation. The need for creativity and the use of digital technologies may be more valuable in digital entrepreneurship compared with traditional business since it is driven by ideas and innovations. Digital businesses require a degree of individual and collective creativity to be able to stand out and develop an online/digital presence. As this chapter indicates, creativity and digitalisation are important as companies must innovate faster than ever to keep pace and stay alive in today's hypercompetitive market. This is perhaps even more important in a digital business than a traditional one due to (1) the increasingly growing number of digital businesses, (2) the increase in innovation in the Internet 
and global devices, (3) the development of a new consumer who is more technically sophisticated and globally interconnected, (4) the advent of new industries and (5) the rapid increase in emerging markets.

\subsection{Digital Technologies Supporting Creativity}

The digital age presents a different challenge to the existing view on the nature of creativity. Online creativity and audiences are affecting the meaning, expression and impact of creativity. Although many studies have been conducted on creativity, the majority of studies still focus on traditional ways of stimulating creativity. This opens up a discussion about the different roles that these technologies play in regard to creativity and the potential for personal and collaborative creativity. In addition, there is a need for research that does not just embrace technology but also critically examines the relationship towards Information and Communications Technology (ICT) and digitalisation (Pedersen et al. 2019). Existing research has highlighted the importance of effectiveness and novelty as two fundamental criteria for creativity. In digital or social advertising agencies, most practitioners regard interactivity as the most important criterion for creativity. Therefore, the degree of interaction of digital technologies should be considered when exploring the relationship with creativity (Chen et al. 2019).

While selecting the digital technologies that support creativity for further detailed examination in this paper, we analysed the general trends and predictions with regard to digital technologies that transform the way we live, from everyday tasks to complex, large-scale projects. The usage of such technologies helps with the decoupling of location, meaning creativity can be exploited from anywhere, whether in transit, at home or anywhere with access to a phone/computer. For further examination, we chose the following arguments for AI, the IoT and VR, which will shape the future of machine learning and automated systems (see Table 1).

Digital technologies, such as AI, VR and the IoT, are reshaping the way in which people live, learn, work and generate ideas and have increasingly become a fascination for individuals, society and companies (Bruno and Canina 2019a, b). Digital technologies are reducing the cost of iteration and experimentation in creative work, which opens up new possibilities for both individuals and businesses (Austin 2016). A global study done by Adobe found that businesses that invest in creativity experienced increased employee productivity (78\%), satisfied customers $(80 \%)$, produced a better customer experience $(78 \%)$, fostered innovation $(83 \%)$ and were financially successful (73\%) (Adobe 2016).

Next, we introduce each technology and elaborate on its role in supporting the creativity of entrepreneurs and their teams. 
Table 1 Characteristics of artificial intelligence (AI), the Internet of things (IoT) and virtual reality (VR) impacting businesses

\begin{tabular}{|c|c|}
\hline Digital technology & Characteristics \\
\hline $\begin{array}{l}\text { Artificial } \\
\text { intelligence (AI) }\end{array}$ & $\begin{array}{l}\text { - The global AI software market is expected to reach } 126 \text { billion USD } \\
\text { in } 2025 \text { and is forecasted to experience massive growth in the coming } \\
\text { years (Liu 2020) } \\
\text { - Artificial intelligence will account for almost } 70 \% \text { of the global } \\
\text { economic impact by } 2030 \text { (Rao and Verweij 2017) } \\
\text { - Thirty-seven per cent of organisations have implemented some form } \\
\text { of AI, which is a } 270 \% \text { increase over the last four years (Stamford } \\
\text { 2019) } \\
\text { - It is estimated that in 2020, } 9.6 \text { billion US dollars will be spent on } \\
\text { intelligent process automation. In this context, AI is autonomous } \\
\text { decision-making through a system or systems designed to simulate } \\
\text { human thought processes (Liu 2020) } \\
\text { - } 51 \% \text { of marketers are already using AI, while } 27 \% \text { of them are } \\
\text { planning to incorporate it within their digital marketing strategy } \\
\text { (Leftronic 2019) }\end{array}$ \\
\hline Virtual reality (VR) & $\begin{array}{l}\text { - The global VR market is expected to reach } 56.25 \text { billion USD by } \\
2025 \text { (Globenewswire 2020) } \\
\text { - It is estimated that in 2025, } 87.97 \text { billion USD will be spent on VR } \\
\text { (Mordorintelligence 2020) } \\
\text { - Globally, there are over } 171 \text { million users of VR in } 2019 \text { (Petrov } \\
\text { 2019) } \\
\text { - Globally, } 18 \text { million standalone VR devices will be sold in } 2022 \\
\text { (Petrov 2019) } \\
\text { - Global standalone VR devices will grow } 16 \text { times between } 2018 \text { and } \\
2022 \text { (Petrov 2019) }\end{array}$ \\
\hline $\begin{array}{l}\text { The Internet of } \\
\text { things (IoT) }\end{array}$ & $\begin{array}{l}\text { - Global spending on the IoT is expected to reach } 1.1 \text { trillion USD by } \\
2023 \text { (Liu 2020) } \\
\text { - The global industrial IoT market is expected to reach } 14.2 \text { trillion } \\
\text { USD by } 2030 \text { (Weber 2019) } \\
\text { - There are expected to be } 21.4 \text { billion IoT devices in the world by } \\
2025 \text { (Liu 2020) } \\
\text { - Cellular IoT connections are expected to reach 3.5B in 2023, } \\
\text { increasing at a CAGR of } 30 \% \text { (Columbus 2018) } \\
\text { - Seventeen per cent of the global respondents identified the IoT as the } \\
\text { top technology game-changer in driving business transformation } \\
\text { (KPMG 2018) }\end{array}$ \\
\hline
\end{tabular}

\subsection{Artificial Intelligence}

Artificial intelligence is one of the most mysterious and fascinating technologies of our time. Many might know the term AI; however, the majority of people would not understand what exactly AI refers to. For a definition, we look towards Copeland (2020), who defined AI as 'the ability of a digital computer or computer-controlled robot to perform tasks commonly associated with intelligent beings'. Copeland (2020) further expands on this by elaborating on the components that make up 
intelligence, such as learning, reasoning, problem solving, perception and language (Copeland 2020). The definition of AI changes throughout the literature, and a specific definition has yet to take hold. In the latest Artificial Intelligence Special Report, published by The New York Times, it was suggested that we are currently witnessing a supervised-learning revolution in which computers are taught to see patterns and learn on their own (Smith 2020).

Moreover, also being relevant to the topic are the Gartner 2019 top Hype Cycle trends in AI, which are augmented intelligence, chatbots, machine learning and intelligent (enterprise) applications, among others (Goasduff 2019). Gartner predicted that in 2020, chatbots would be responsible for $85 \%$ of customer service (Milenkovic 2019). Accenture believes that AI will not only increase businesses financial gains, going as far as doubling economic growth by 2035, but also drastically change the way people work. Their research suggests that $40 \%$ of business leaders believe that AI will increase worker productivity in the future (Milenkovic 2019). This is great news for entrepreneurs and their teams, as AI will most likely assist in maximising their employees' output while maintaining a good work-life balance (Milenkovic 2019).

Considering how AI supports creativity, there have already been several exciting developments, one of which has taken place in one of the arguably most creative fields of human expression: art. Artificial intelligence has already begun creating music, painting and designing fashion (Magalhães 2019). Examples of this can be found in music studios, where AI is now helping in the mastering of songs. Expanding further into art, AI can now create original paintings and rework existing pieces of art, which would have simply not been possible a few decades ago (Marr 2020). There is now AI capable of sifting through enormous amounts of data and creating something new with a handful of the data that it had just analysed. A painting created by AI in 2018 sold for $\$ 432,500$ USD at a Christie's auction. This might not be a very impressive sum to an art enthusiast; nevertheless, considering the fact that it was not created by a human makes it quite impressive (Magalhães 2019). Another example of creative use of AI in business is the world's first robot artist, who already held her first solo exhibition, equipped with facial recognition technology and a robotic arm system (Haynes 2019) or algorithms can read recipes and create images of what the final dish will look like, supporting the cooking process (Whyte 2019).

According to Nicola Morini Bianzino, EY Global Chief Client Technology Officer, AI can encourage human creativity in freeing up time for humans to focus on innovation, thereby offering opportunities to creatively combine technologies to create new ways of working and actively augmenting human decision-making by adding a layer of machine-driven data analysis to guide our creative choices (Bianzino 2020). However, AI is not meant to wander off and create art for the rest of its days. What constitutes the interesting element of AI when examining creativity is how it can enhance the creativity of creatives, such as artists, musicians or professionals. To create one of AI's components, machine learning (ML) might be the most interesting. Machine learning makes it possible for an artist to feed the AI piles of data that it can then analyse. The AI will then provide the artist with a range 
of options for starting points, rather than having to think of a starting point themselves. Artists would no longer be limited by the ideas they get but rather by their ability to translate the ideas of an AI into a work of art (Magalhães 2019).

Interestingly, Forbes speculated that AI would level the intellectual differences of individuals. Individual IQs will decrease in importance, as AI will aid those with lower IQs. Moreover, the conclusion is that creativity and imagination will become increasingly important in the years to come. Forbes reports that the World Economic Forum made a prediction in 2016 that creativity would be the third most important skill to employers in 2020. Creativity previously held the 10th place in 2015 (Fatemi 2018). Another important aspect of AI mentioned by Forbes is that AI alleviates people from the mundane, time-consuming and repetitive tasks that might take an employee days or weeks to complete. Relieving an employee of these tasks will greatly increase the time they have available for creative endeavours (Fatemi 2018). However, we must consider the limits of technologies such as AI at this time, since much is yet to be learned about its capabilities and uses. For example, the dangers of integrating AI into our daily lives must be explored, as it could bring risks that are not yet foreseeable.

In conclusion, AI can be seen as a catalyst to push human creativity. While machine and human collaboration can produce exciting results, novel approaches and combinations would not likely develop if either were working alone (Marr 2020). Moving beyond its simple existential purpose of analysing vast amounts of data, AI has the potential to become humanity's best tool for advancing itself creatively and does so by stimulating entrepreneurial minds to find entirely new ways to utilise data.

\subsection{Virtual Reality}

Constructs such as VR, augmented reality (AR) and AI are often regarded as similar and interchangeable, which can stop managers and entrepreneurs from exploring their potential and effectiveness. To avoid any confusion between AR and VR, we would like to clarify the difference (Marr 2018). Augmented reality is already widely used in business processes and departments that benefit from technological solutions. In business and management, it is often difficult to distinguish the differences between new available technologies. Understanding the differences between different virtual, physical and possible constructs is crucial for successful integration of such technologies in business processes. Hence, a clear definition of $\mathrm{AR}$ is provided before exploring its relation to creativity and overall benefits and risks. Moreover, AR is the integration of digital information in a real-world environment, such as virtual, statistical and auditory content. A layer of digital information is made accessible to people and is generated by computer software (Farshid et al. 2018). This technology can be provided for a wide range of uses and platforms. Most popularly used are applications on smartphones or other devices and wearables. The layers that are added to the actual world can be both sensory and data-based. Augmented reality technology can provide various solutions for both 
businesses and consumers. This technology is already a popular tool used by both start-ups and large corporations, offering utility for a wide range of purposes.

Unlike AR, VR represents a full digital representation of the actual world with virtual content and information. Virtual reality is a complete virtual replacement of the real world, whereas AR adds content to it (Farshid et al. 2018). This could be a three-dimensional (3D) digital environment generated by computers, which can be used for different purposes. A popular function is the ability to play videogames and view immersive video content through VR headsets. In a business context, however, VR technology can be used to make creative content. Businesses are looking for digital solutions for automation and productivity for their internal processes.

There are many success stories regarding the implementations of VR technology in which the technology has increased productivity and creativity in external and internal processes. Several VR-supported approaches have been tested to examine its effects on creativity. Alahuhta et al. (2014) identified eight affordances for the support of creativity by virtual environments. Characteristics of VR technology, such as immersion and rich visual information, were determined to be important aspects to support creativity. In experiments conducted by Lau and Lee (2012), a focus was put on learning creativity and the support of learning experiences. From experimenting with highly interactive virtual environments, it showed that entertaining and explorative factors were essential. Another VR-supported approach concerning creativity that primed virtual environments was tested by Bhagwatwar et al. (2013). Here, the idea-generation process of humans was investigated by exposing them to these virtual environments. Graessler et al. (2017) tested six generated virtual environments, consisting of different contents and grades of mobility and interaction. As a consequence, Graessler and Taplick (2018) tested the Sensory Stimulus Environment Technique with pre-developed virtual environments to investigate its efficiency. By comparing this technique with 'brainstorming' and the Sensory Picture Technique, they were able to improve the creativity technique supported by VR technology. These approaches have assisted in the exploration of the relationship between creativity and virtual environments. Moreover, a common example is the use of virtual tours of houses and other properties in the real estate industry. Real estate firms are now able to offer creative digital content in the form of VR tours that allow potential customers to get a realistic and immersive impression of the property. When integrated successfully, VR technology can replace harmful or complex situations in terms of training. Like AR, this technology can also provide solutions for remote access and communication, which can standardise certain operations and reduce the carbon footprint (Fade 2020).

Visual tools and technologies are effective ways to foster creativity in business model development processes and idea development. Augmented reality can help us visualise data and information in the real world to give a realistic perspective of an idea or concept. Digital technologies such as AR enable entrepreneurial activities and ease the process of bringing ideas to life or improving communication and other processes (Elia et al. 2020). One of the great purposes of augmented reality is the visual aid to support departments and customers. Many firms have explored the use of augmented reality to bridge the gap between working with customers remotely. 
As an example, the global medical technology firm Becton Dickinson required an augmented reality software to aid the field engineers and medical firms that rely on their products. Becton Dickinson uses the software Help Lightning, which allows them to give remote assistance and support through an application on a tablet that shows data and visual content about their machines (York 2020). Moreover, the laboratory technician can see the hands of the experts while being guided through the process of inspection, maintenance or repair. Augmented reality enhances interaction and the visualisation of ideas, which allows for increased creativity. It shows great potential in adding value for external activities, such as customer support and marketing, as well as internal business activities like design, cooperation and efficiency (van Lopik et al. 2020). This technology not only benefits creative industries, such as arts, music, architecture or design, but can also be creatively utilised in any industry in various forms.

Additionally, AR is a creative learning method that is very effective for training employees. Training with integrated AR technologies is more immersive and interactive, which can make employees more effective and time-efficient (Hamdouna 2018). It allows trainees to use their imagination and give their input through digital content, which boosts overall creativity and collaboration. These benefits are further reinforced by the ability to simplify difficult processes and instructions. A potential risk is a reliance on such technologies in important processes, such as customer support. If the software does not work or is not understood by both parties, it can lose its value and may require personnel support. However, technological advancement in the future will provide many opportunities for AR technology, as it could be integrated into many different daily usages both commercially and privately. In a matter of years, this tool has grown from its early adoption stage to standardisation in various industries and will continue to have a great impact on creative processes.

\subsection{Internet of Things}

According to Ernst and Young Americas (2018), the introduction of connected technologies over the last decade has changed our lives. Across all manner of physical objects, sensors are being embedded that can track and share information, self-optimise and learn how to better perform - with or without human intervention, creating a truly connected world of the IoT (EY Americas 2018). The IoT not only impacts many aspects of daily life but also leads to new opportunities for businesses. This means that new needs and types of consumers will continue to emerge, and new innovations and ideas will emerge to meet those needs. Businesses that can fully adopt the IoT will be able to improve their bottom line by growing their overall productivity, lowering operating costs or entering new markets (Phaneuf 2020). The IoT allows for greater connectivity and the collection of data but will also have a significant effect on creative processes.

To explore the relationship between the IoT and creativity, the different purposes of using such technologies in creative processes should be considered. Additionally, 
the importance of combining data and creativity in today's digitalised society is emphasised. The creative use of collected data on customer behaviour and preferences will determine the success of new innovations and business models. For instance, in a marketing context, the IoT will have a significant impact on creativity in designing advertising campaigns. Marketers will be able to grasp every need of every individual customer that will share his or her preferences and information via IoT devices (Hu 2015). An example of this can be the use of programmatic ads that could be highly personalised and published in a timely manner. The IoT means that any object can be connected to the Internet and retrieve data. Like AI, this will allow for revolutionised ways of gaining customer insights and offering creative marketing content that is personalised to every individual's needs. However, the technology could be integrated into much simpler objects, such as an electric toothbrush. The connected toothbrush can collect data on usage patterns and ultimately make suggestions or offerings to the customers, such as changing the brush or scheduling a dentist appointment. Rather than simply pushing advertisements, the IoT can work as a tool to accordingly time the offering to add value to the right moments when customers need it. The timing of such moments will play a significant role in customer satisfaction.

No matter what role technology plays, it still comes down to the creative abilities of marketing departments and idea development. The effective and holistic adoption of the IoT in management is perhaps the greatest barrier to overcome. Many firms still struggle to apply such technologies, as well as to reshape their business model to become more meaningful and sustainable. To effectively connect both data and creativity, businesses must maintain a more holistic approach. This means that creative departments should be able to make use of such technologies and have access to data, whereas departments working with data should be empowered to think creatively (Balis 2018). Namely, data provides business with insights into customers to anticipate their needs, which can reduce clutter and refine advertising. Creative processes working with the IoT should be encouraged across all platforms and will become more machine-driven in order to generate ideas based on content from acquired data. Moreover, the IoT draws a blueprint that every device in our lives will eventually be connected to the Internet and function as a sensor for data collection, which is reinventing creativity with billions of IoT devices around the world.

\subsection{Supporting Creativity Through Digital Technologies}

The digital age appears to challenge much of the existing work on the nature of creativity. Digital technology and related ICT can be seen as a set of tools to be used when appropriate in the creative process. Information and Communications Technologies provide new tools, media and environments for entrepreneurs and employees to be creative. Through ICT, imagination, expression, autonomy and collaboration can be heavily reinforced. Information and Communications Technologies, when fully taken advantage of, can give purpose and foster originality. 
Table 2 Distinguished features of digital technologies, including artificial intelligence, virtual reality and the Internet of things, used to support creativity

\begin{tabular}{l|l}
\hline Feature & Characteristics \\
\hline Automatic functions & Selecting a variety of ideas or pre-screening processes \\
\hline Capacity and range & $\begin{array}{l}\text { Spacing the ways in which it affords access to vast amounts of } \\
\text { information locally and globally in different time zones and } \\
\text { geographical places }\end{array}$ \\
\hline Evolvement & $\begin{array}{l}\text { Greater processing capacities, leading to dramatic } \\
\text { price-performance improvements and lower costs }\end{array}$ \\
\hline Flexibility & Easiness to use or reconfigure the data \\
\hline Interactivity & $\begin{array}{l}\text { Involving users at a number of levels, from the playing of a } \\
\text { game, which gives feedback on decisions made, to the } \\
\text { monitoring of a space probe through immediate and dynamic } \\
\text { feedback is provided }\end{array}$ \\
\hline Provisionality & $\begin{array}{l}\text { Enabling users to make changes, try alternatives and keep a } \\
\text { 'trace' of the development of ideas }\end{array}$ \\
\hline Speed & $\begin{array}{l}\text { Allowing tasks of storing, transforming and displaying } \\
\text { information to be carried out by the technologies, enabling } \\
\text { users to read, observe, interrogate, interpret, analyse and } \\
\text { synthesise information at higher levels }\end{array}$ \\
\hline Unpredictability/generativity & $\begin{array}{l}\text { Provoking changes in technologies' overall capacity, which } \\
\text { are driven by large audiences that can disrupt industries }\end{array}$ \\
\hline
\end{tabular}

Information and Communications Technologies offer new opportunities to be creative in novel contexts and in ways that were previously inaccessible without the recent developments in technology. Admittedly, the term digital technologies is broader than ICT. Digital technologies exhibit numerous features that enable users to do things that could not be done as effectively, or at all, using other tools, and digital technologies provide features that can be further exploited by users to make a distinctive contribution to entrepreneurial activities (see Table 2).

Digital technologies exhibit numerous features, as presented in Table 2, which enable entrepreneurs, employees and users to do things that could not previously be done as effectively, or at all, using other less sophisticated tools.

Next, we will elaborate on a variety of ways in which digital technology can enhance innovation by facilitating the conditions necessary for the development of employees' creative ideas and the implementation of these ideas in organisations. We begin by arguing that three conditions are necessary for employees to generate creative ideas (1) access and exposure to new and diverse information, (2) full engagement in the work role and (3) the experience of socioemotional or instrumental support. We posit that the implementation of employees' creative ideas requires the mobilisation of support and sponsorship of the ideas from credible allies. As such, we discuss the possibility that digital technology shapes the degree of creativity of ideas generated by employees and the implementation of these ideas by influencing each of these conditions. Digital technologies with the abovedescribed features have also been used to support the early stages of imaginative 
play, speculation and 'brainstorming', which all together help to unleash the creativity of entrepreneurs and their teams.

There is a great deal of evidence that suggests that technology enhances creativity (Kapoor 2019). Research has shown empirically how the Internet environment and the advent of new digital technology have altered the cognitive behaviours and structures involved in information processing, executive control and reward-processing (Bruno and Canina 2019a, b). Individual creativity and group creativity are both important to sustaining an innovative environment. The latter has been affected in many positive ways by the rise of digital platforms and the tools for better communication. Moreover, digitalisation has influenced idea creation and implementation in many ways. The digitalisation of information exchange and communication techniques have had a great impact on the exchange of ideas and decision-making processes. These technological developments have improved group work efficiency and communication, which can be beneficial to the successful realisation of new business ideas. Since creativity is at the heart of an organisation's innovative capabilities and its ability to grow, its importance must always be considered. Often, employers and employees may feel pressure to achieve their financial targets and goals within a given timeframe, which makes it difficult to prioritise creativity daily. Managers must offer teams sufficient time and space to let their creativity be involved in their daily work and problem solving (Brodherson et al. 2017). An organisation should also be open to allow technology to drive its business processes and foster a company culture. It is important for individuals of an innovative firm to be flexible and ready to adapt to continuous forms of change. Technological innovation occurs more often than breakthrough innovation and can be continuous. Firms should offer training to employees as soon as new technologies are integrated into the business processes. Furthermore, employees could also suggest the use of new technologies at the firm when possible. New applications and other forms of communicative platforms continue to change and improve, some being more beneficial than others.

Management should be open to creative ideas from their employees on new digitalisation opportunities. As mentioned above, new technologies may improve communication in terms of efficiency and allow peers to give their creative input. The encouragement of creativity can also be applied through the use of stimulating environments or practices. For example, inspiration for new ideas can be fostered through activities that do not directly relate to daily tasks. Innovations and ideas tend to originate through the creation of environments in which ideas of individuals are able to connect and feed each other. This may give rise to different perspectives and insights on the problem. Firms that are able to form a team with different perspectives allow these individuals to challenge and support one another. Such an environment can directly quicken the process of innovation and may be a very important factor in today's world of constant change. This can be achieved by allowing individuals to experiment and to step out of their comfort zones (EY Global 2018). Another way in which digitalisation within companies is encouraged is the pressure from competitors. Many industries have been disrupted by the introduction of digitalised and innovative business ideas. One example is the 
success of Uber, which has disrupted many taxi industries worldwide. The market is now being redefined, largely as a result of technological factors. Uber has also given rise to many similar ride-sharing services, such as Lyft. These services connect drivers and customers through an online platform and mobile application, which is very different from traditional taxi services (Cramer and Krueger 2016).

In conclusion, we would like to discuss some possible risks of digital technology use. Artificial intelligence, among others, brings great risks to our way of living once it is fully developed, as there is a fear of being replaced by intelligent machines (Frey and Osborne 2017). Many argue that continuous innovation and the integration of technologies could mean that we will one day be replaced by intelligent machines. Sharing creativity and posting is not always positively received. It can be argued that digital technology creates higher levels of distraction. For example, SNS users often create posts for short-term amusement, causing alarm or eliciting controversy. Moreover, SNS memes go viral and are shared across huge networks. These memes and jokes are expressive, but they are forgotten as quickly as they are generated (Gardner and Weinstein 2018). The remixing and rapid dissemination of these personal works in NDM have diminished the importance of traditional notions of appropriateness and authorship of media (Gardner and Weinstein 2018). More seriously, designers of technology, executives and researchers have all recently expressed their concern about the implications of an attention-based economy being the basis for business models focused on digital tools. The goal of maximising users' time online can result in the malicious hijacking of the mind, via the monetisation of thoughts, emotions and actions with potentially serious consequences for mental health, relationships and democracy.

Digital technologies can and do exploit human vulnerability and reduce autonomy through addiction by design, which might have significant implications for the creativity of entrepreneurs and their teams. Hence, the digital realm offers new arenas and opportunities for group engagement, from which creativity can emerge, but also new dilemmas about the value and purpose of creative work and how to distribute it respectfully.

\subsection{Digital Creativity Model}

Given the many definitions of creativity, it is difficult to imagine that an accepted definition of digital creativity will emerge, and it is even more difficult for digital creativity to emerge in entrepreneurship, particularly since terms have different descriptions and meanings across disciplines.

One model of digital creativity is proposed in Fig. 1, showing the key dimensions (participating, making, compose, code, edit, curate, perform, author and producer) and their relationships with each other.

The first line of the model, the activity which has the aspects of participating or making, indicates that there are different levels of intensity of engagement at different periods of time. An entrepreneur will typically be leading (making) the creative activity but will also be involved in creative digital activities initiated by 


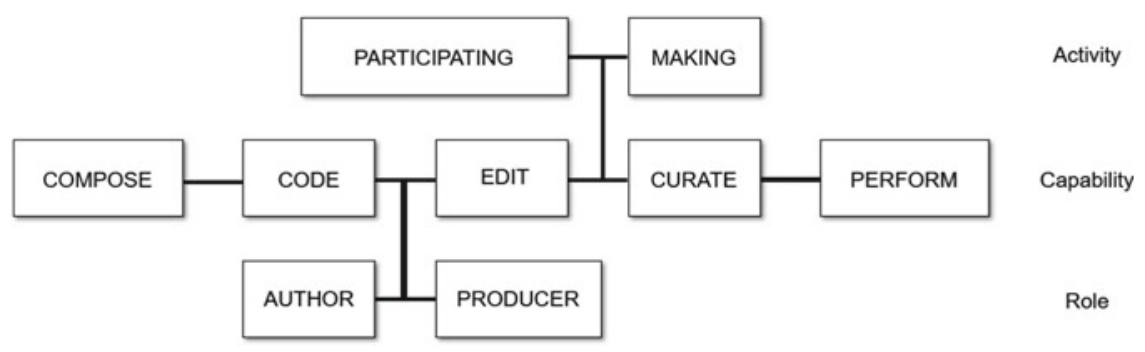

Fig. 1 Digital creativity model. Source Sefton-Green (2018)

members of his or her team and other employees throughout the organisation (participating). The more the entrepreneur can create an environment in his or her organisation that provides the atmosphere for more and more creativity to occur, the more the results will be creative projects that he or she can be involved in through participation.

The second line of the model, capability, involves various roles, such as compose, code, edit, curate and perform. Typically, this indicates that often, entrepreneurial digital creativity involves a complex team with different job specifications. While some creative activities in an entrepreneurial environment will not require all five roles to be present when developing a new product or service, each role is needed. Some individual(s) in the entrepreneurial organisation must generate a new idea or a new way of doing things (compose), develop the idea into something actionable (code), refine the idea through test marketing and evaluations at various stages of the product development process (edit), accumulate the various parts, equipment and procedures to make the idea into a marketable product or service (curate), and then ensure the customer is satisfied with the results (perform).

The third line of the model is the entrepreneurship role that involves the position of the entrepreneur and creates the team. Is the role more of being the creator of the idea (author) or being able to develop and market the new idea for a product or service (role). It will be interesting to view the models that develop as a result of the use of digital technologies in areas of marketing, such as consumer purchasing process, product planning and development, pricing, distribution systems and promotion.

It is important to realise that all three components of this model are interdependent and must be balanced in order for the potential of digital creativity to be unlocked. The level of engagement must match the capabilities of entrepreneurs and their teams, who in turn, must take on a role that can effectively convert the first two components into creative output. This will ensure that the resources used to attain said output are appropriate and that such resources are available and not wasted. If an entrepreneur, for example, were to not put themselves in the right role and then create an environment that is poorly chosen for creativity maximisation, no team, no matter how well-chosen and complex, will be able to provide the entrepreneur with the creative output they desire. 


\section{Examples from Practice/Case Studies}

\subsection{Brandmark: Developing a Logo and Brand Using Artificial Intelligence Software with Brandmark}

Brandmark.io is a smart logo-generating tool based on AI technology. It is a tool that shows the technical possibilities of AI and its impact on creative processes. This case illustrates how the design of visual elements can be creatively developed with the use of digital technologies. The firm was founded in Vancouver, Canada, by electrical systems engineer and web developer Jack Qiao, who has developed a series of AI-powered design tools (Loper 2018).

The Brandmark website offers various AI tools for making a creative logo. One AI-powered tool on the Brandmark web application is called the AI Colour Wheel. The AI Colour Wheel automatically colourises logos, illustrations, wireframes and other graphic art (Brandmark 2020). Brandmark uses deep learning tools to generate logos composed of an icon, typography, colour scheme and specifications made by the user. The specific technologies used are ConvNets, word embeddings and GAN. The technology uses machine learning to generate logo idea presets that consider the specification and preferences made by the user. Brandmark's neural net approach can group highly similar icons, and its derived legibility score and uniqueness score are able to find legible and less-common shapes. Another system driven by $\mathrm{AI}$ is the logo rank tool. It is programmed on over one million images to give the user tips, inspiration and ideas. In addition, it can be used to check if your designer took inspiration from stock icons. The third AI tool is called the logo crunch tool, which uses computer vision to make high-resolution logos legible at lower resolutions. This tool is useful in making icons and logos that work on both high and low resolutions and different scales. Overall, it makes the process of creating separate logos for each size much easier than other online-based logo generators, since these mostly use the naïve scaling method. The font generator is another smart tool offered on the Brandmark website. It produces unique font pairings from Google fonts. All of these smart AI tools significantly simplify the logo creation process and deliver high visual quality.

The use of quality and original visuals is very important in brand development. Uniqueness and legibility are crucial elements of logos to be brandable. They should stand out and be recognisable. Small business owners looking to re-brand are the main target audience for Brandmark. It is a cost-effective way to create visuals for a new brand since it does not require human labour. However, the premium 'Enterprise' bundle gives the buyer up to 10 original concepts created by Brandmark's in-house design team. Moreover, the AI logo design process is very time-efficient, as it produces professional design ideas in a matter of minutes. This process only requires three simple steps in which certain preferences, such as keywords, business name and tagline, and colour styles, are taken into consideration. Then, the given presets can be further edited to the user's preferences, such as 
the logo, font and colour. The logo-making process is free, and payment is only required when the user wishes to download it.

Despite Brandmark being one of the most capable and innovative logo-makers available to date, it still maintains its limitations and risks. The effect of AI technologies on an individual's creativity is still subject to further research. Technologies, such as Brandmark, use smart AI tools to make the design process easier and faster. However, the level of creativity remains subjective. It comes down to human judgement, which is currently still beyond the capabilities of AI technology (Ghoshal 2017). Nevertheless, AI can help to pick and gather many different ideas that can lead to creative innovations. It can help to ingest, store and access unprecedented numbers of ideas to aid human creativity and input (Uzzi 2019). Another benefit of AI is that it is not prone to certain biases and gathers ideas in systematic ways. Artificial intelligence technologies have been proven to be effective tools for thinking outside the box and collect ideas based on algorithms in ways that human minds are not able to. Therefore, AI technologies, such as Brandmark, have the potential to assist human creativity and contribute to breakthrough ideas and innovations. Many people would suggest that logos created on the Brandmark website or similar services are too generic. Its biggest constraint is the ability to find logo ideas and icons that are not commonly used. It raises the question of whether AI technology is yet capable of replacing the creative input of humans, or whether it is a possibility in the near future. For now, Brandmark functions as a helpful tool to create design ideas.

\subsection{HOK: Empowering Creativity Through the Powerful Use of Virtual Reality as a Creative Tool for Architects and Designers}

Founded in 1955, HOK is a global design, architecture, engineering and planning firm. Across the USA, EMEA and APAC, the 1800 employees of HOK, based in 24 different offices worldwide, use design to help clients succeed and create places that enrich people's lives (HOK 2020). HOK has won multiple awards, including NCSEA Awards Firms for Structural Engineering Excellence 2019 Category 6 (Long 2019) and CRE Awards 2019: Best Tenant Improvement Project (Los Angeles Business Journal, 2019 and Fast Company's Most Innovative Companies list in 2019). HOK has some famous projects under its belt, including the LaGuardia Airport New Terminal B in New York, Mercedes-Benz Stadium in Atlanta, Georgia and the King Abdullah University of Science and Technology in Thuwal, Saudi Arabia, that all stood out for their creativity.

Virtual reality is used at HOK in many different ways to improve clients' understanding, interaction and relations, but also to make more detailed and enhanced prototypes (Howarth 2018). As an architecture firm, the relationship between the client and project leaders is very important. It can be difficult for architects to help clients understand technical plans since clients do not always have the same knowledge and visual imagination that architects and engineers have 
(Howarth 2018). Virtual reality also creates new opportunities for client feedback in the design process. Below, we have listed ways that VR is leveraged as a creative resource at firms like HOK.

First, VR enables architects and engineers to articulate concepts to their clients through a more experiential medium. Using advanced technology, architects can help clients better understand complex architectural plans, sections and design concepts.

Second, architects receive better feedback from clients when the client can visualise design concepts. Virtual reality encourages participation in the creative process, allowing the client to share more accurate and candid feedback with the architects.

Third, visualisation tools can contribute to an architect's creativity, as they are able to explore the space they have designed. Furthermore, VR can allow the architect to better spot possible errors or flaws in their designs.

As VR technology evolves, it plays an increasingly important role in the design process. HOK has even developed its own VR app, available to anyone in the industry or general public for free, which aims to better facilitate leveraging the technology for the design process. The app allows for increased collaboration, as multiple clients can view spaces simultaneously and provide real-time feedback. From allowing architects to create more detailed fvisualisations involving clients in the creative process, the technology can impact project outcomes, verify adjacencies and desired workflows within spaces and benefit client relationships.

The above case has been prepared in cooperation with HOK. We would like to thank Annie Merrill and the team for their useful insights.

\subsection{Scandit: Offering Computer Vision for the Modern Enterprise by the Internet of Things}

Established in 2009, Scandit is a Swiss company that develops software for mobile enterprise apps with high-quality barcode scanning, text and object recognition as well as augmented reality solutions (Scandit 2020). Serving customers and partners across the USA, EMEA and APAC, Scandit provides billions of scans per year, making it a trusted market leader (Scandit 2020). With a vision to bring the IoT to everyday objects, the company wants to converge the physical and digital worlds by creating machines that can identify everyday objects that are not connected to the Internet. At Scandit, the 200+ employees produce an estimated 32 million USD in revenue (Owler 2020), covering organisations present in over 80 countries (Science Business 2013).

Scandit is using the IoT to connect objects through smart device technology. The company has developed data capture software, which turns smart devices equipped with a camera into universal sensors. These sensors can identify barcodes, creating opportunities for companies and consumers who can, in turn, improve their productivity and drastically improve their quality of life (Scandit 2019). The technology of Scandit enables companies and consumers to get creative by connecting 
the physical world to real-time data through smartphones, tablets, drones and robots. It has been applied in industries like health care, manufacturing, retail, and transportation and logistics (Butcher 2017; Sawers 2018; Scandit 2019; Science Business 2013).

In terms of creative solutions, Scandit provides many opportunities for retail stores on how to upgrade their retail processes. In the past, before Scandit's solutions were offered, retail stores used various devices to scan barcodes that were unnecessary and costly being a bottleneck for the supply chain from warehouses to consumers. Due to the economies of scale, personal smart devices have faster innovation and better performance. First, these personal smart devices can be used instead of the barcode scanning devices. It allows the consumer to explore, buy and re-order products anywhere and at any time. Second, it allows the consumer to receive more in-store product information, have a virtual shopping bag and then pay with a click option. Finally, it will allow the consumer to receive personalised discounts.

The software offered by Scandit supports the work of in-store employees, as it allows them to scan barcodes as well as IDs without the need for limited and expensive hardware. Furthermore, it allows the employees to show stock, delivery dates and price verification with a short scan, thereby drastically reducing human error. In the warehouse, it assists employees in receiving detailed inventory management, shipping and receiving dates and the ability to verify stock in a matter of seconds (Scandit 2019).

For Scandit, the IoT software creates new opportunities and creativity, and four of these opportunities are mentioned below. First, through the IoT software, Scandit and its clients, like Coop, Switzerland's largest wholesale company with more than 2300 sales outlets in Switzerland (Coop 2020), can monitor the buying behaviour of consumers. This data can be useful for companies and create new opportunities. For instance, Scandit could monitor the buying behaviour of consumers and create personal discounts. Such data can be further used for designing creative marketing campaigns. These discounts will increase consumer satisfaction and most likely lead to higher client loyalty, thereby increasing sales. Seasonal discounts and combinational discounts could attract consumers to buy more products. Combinational discounts could, for example, allow the consumer to buy a meal that is on sale, instead of just one product. Furthermore, the IoT software could use the data from consumers to make their life easier while highlighting the creative side of the company. When a consumer scans a product, the software could produce many recipes that contain that product. This would allow the consumer to pick recipes within seconds that consist of products at that store. Second, the IoT software could allow the consumer to buy the product it needs for certain diets. For example, when a consumer has a specific medical diet restriction, the IoT could create a pop-up when that product is scanned. This is applicable for medical restrictions or allergies but also for food plans. If a consumer would prefer to live a healthy life, only eat vegan meals or prefer biological products, the IoT would supply the consumer with a creative list of meals and available products to order, either online or at the store. In addition, the IoT software could even know what the consumer has in the fridge 
and supply a list of meals that contain those products, thereby fighting food waste and providing an enriching shopping experience. Third, for stores, the IoT software would drastically increase efficiency. If the IoT is used for inventory management, many new opportunities will arise. For example, through marketing and advertising, the store managers could guide the sale of certain products. This could be useful when certain stock is piling up in the warehouses or when stock is approaching its expiration date. In addition, since it can closely monitor the sales per product, it could improve just-in-time (JIT) management. The IoT software provided by Scandit collects a large amount of data, which, in turn, can forecast the sales of products, making it undoubtedly supportive in managing the demand for the product. Fourth, the IoT would allow a store to easily follow a certain strategy. Today, an increasing number of stores are prioritising their strategy of being cheap, fair-trade or biological. With the IoT software from Scandit, stores are able to filter products from their suppliers based on those characteristics, allowing them to select the desired product instead of searching them manually.

The IoT has an enormous impact on companies and their creative processes, not only in terms of retail and supply chain but also in its ability to be used for other purposes. Concerning Scandit, the opportunities spurned from its IoT barcode software are endless. Scandit has proven that the IoT can be used to boost creativity processes, which ultimately help grow and optimise company processes and relationships with customers.

\section{Conclusion and Implications}

This chapter explores the use of digital technologies by entrepreneurs to support their own as well as that of their teams and other members of their company. Creativity is the ability of an individual or small group of individuals to generate novel, useful ideas and take advantage of new opportunities offered by digital technologies. While there is no doubt about the importance and need for creativity in entrepreneurs and their organisations, the role of digital technologies such as artificial intelligence, virtual reality and the Internet of things in this process is just starting to take shape. The digital technologies being used to date in areas, such as brainstorming, imaginative play, innovation and visual learning exhibit features of provisionality, interactivity, capacity, range, speed and automatic functions. Entrepreneurs, no matter the size and industry of their company, must be open to creative ideas resulting from digitalisation opportunities. While there are risks involved, digital technologies offer new arenas and opportunities for creativity along with new dilemmas concerning the value and purpose of creativity and how the results should be distributed.

As with the beginning of any new era and in the realm of creativity, the era of digital technologies used by entrepreneurs offers many new research activities. The present chapter described the ways digital technologies can impact creativity in an entrepreneurial company, regardless of its size and industry. The case studies 
present the output of this in practice. This chapter provides the foundation for not only the use of digital technologies but also specific examples of its use and results. By focusing on the role of specific digital technologies (artificial intelligence, virtual reality and the Internet of things), the chapter furthers the understanding of the impact of digital technologies on entrepreneurship in general and specifically on the creativity required for the successful start, operation and growth of a new venture. This chapter discusses and illustrates the importance of creativity in digital business as a result of the numerous changes occurring at an increasing rate. Digital businesses will find it difficult to not only compete for sales but also for talented employees. Future research must further refine its use by entrepreneurs, examine various uses across size and industry of the entrepreneurs and their organisations, and develop specific models, rather than the general model proposed in this research, in areas such as the customer purchasing process, innovation, distribution systems and channels, and various promotion activities. Indeed, future research in the area of digital technologies unleashing the creativity of entrepreneurs is promising.

We are all moving towards digital enhancement, and companies should be able to train with, collaborate and interact with digital technologies to generate novel and useful ideas. As the world of digital technologies and human creativity continues expanding, it is time to stop worrying about whether digital technologies can foster creativity and focus on how the human and machine worlds can intersect for creative collaborations that have never been dreamt of. Rather than worry about the rise of AI, VR and the IoT, businesses should embrace the opportunity technology is bringing to unleash a new wave of human creativity and power human enterprise. Such technologies can free up time spent on innovating, provide new combinations of technologies to enable better ways of working and help guide us on the path towards even more effective creative ideas to be implemented in various stages of business. It is therefore fundamental to entrepreneurs and their teams to understand what is happening in the field of creativity, as it is tremendously impacted by digitisation.

Acknowledgements We acknowledge, with much appreciation, the many constructive insights of Daniel Steggerda, Thom van der Meer, Vincent Jochum, the International Business School students at the Hanze University of Applied Sciences.

Daniel, thank you for your great input, commitment and passion, which have altogether increased the quality of this work. We wish you all the best in your future, and we are looking forward to seeing your creativity supported by digital technologies in action.

Thom, thank you for your valuable input throughout this chapter, providing content and literature with great insight and commitment. With relevant research and writing, your input has been valuable in guiding the direction of the project and finalising this chapter. We wish you all the best and hope to see you utilise your knowledge on entrepreneurship and digital creativity in the future. Vincent, thank you for your contributions to finalise the chapter. Thank you for your useful insights in artificial intelligence and input throughout the chapter. We hope to see you put your entrepreneurial mindset to great use, and we wish you the best in your future. 


\section{References}

Adobe. (2016). State of create: 2016. https://www.adobe.com/content/dam/acom/en/max/pdfs/ AdobeStateofCreate_2016_Report_Final.pdf.

Alahuhta, P., Nordbäck, E., Sivunen, A., \& Surakka, T. (2014). Fostering team creativity in virtual worlds. Journal for Virtual Worlds Research, 7(3).

Amabile, T., \& Khaire, M. (2008). Creativity and the role of the leader. https://hbr.org/2008/10/ creativity-and-the-role-of-the-leader.

Austin, R. (2016). Unleashing creativity with digital technology. https://sloanreview.mit.edu/ article/unleashing-creativity-with-digital-technology/.

Balis, J. (2018). Why tomorrow's media must combine creativity and data. https://www.ey.com/ en_gl/digital/why-tomorrow_s-media-must-combine-creativity-and-data.

Bhagwatwar, A., Massey, A. \& Dennis, A. R. (2013). Creative virtual environments: Effect of supraliminal priming on team brainstorming. In 2013 46th Hawaii international conference on system sciences (pp. 215-224). IEEE.

Bianzino, N. (2020). Is AI the start of the truly creative human? https://www.ey.com/en_eg/ai/isai-the-start-of-the-truly-creative-human.

Brandmark. (2020). AI Color Wheel. https://brandmark.io/color-wheel/.

Brodherson, M., Heller, J., Perrey, J. \& Remley, D. (2017). Creativity's bottom line: How winning companies turn creativity into business value and growth. https://www.mckinsey.com/ business-functions/mckinsey-digital/our-insights/creativitys-bottom-line-how-winning-companiesturn-creativity-into-business-value-and-growth.

British Council. (2020). Defining Creativity: Literature review part 1. https://www.britishcouncil. org/programmes/creative-play/defining-creativity-literature-review-part-1.

Butcher, M. (2017). Scandit, which replaces barcode scanners with phones, closes $\$ 7.5 \mathrm{M}$ from Atomico. https://techcrunch.com/2017/01/10/scandit-which-replaces-barcode-scanners-withphones-closes-7-5m-from-atomico/.

Bruno, C., \& Canina, M. (2019). Creativity 4.0. Empowering creative process for digitally enhanced people. The Design Journal, 22(sup1), 2119-2131.

Bruno, C., \& Canina, M. (2019). Creativity 4.0. Empowering creativity in the digital era. In DS 95: Proceedings of the 21st International Conference on Engineering and Product Design Education (E\&PDE 2019), University of Strathclyde, Glasgow, September 12-13, 2019.

Cardwell, J. (2020). Luckin coffee sets the table for continued growth. Nasdaq. https://www. nasdaq.com/articles/luckin-coffee-sets-the-table-for-continued-growth-2020-01-19.

Chamorro-Premuzic, T. (2015). Is technology making us more creative? The Guardian. https://www.theguardian.com/media-network/2015/jun/18/technology-creative-creativity-webcontent.

Chen, H., Wang, R., \& Liang, X. (2019). Americanized or localized: a qualitative study on Chinese advertising practitioners' perceptions of creativity and strategy in the digital age. Global Media and China, 4(2), 233-253.

Columbus, L. (2018). 2018 roundup of Internet of things forecasts and market estimates. https://www.forbes.com/sites/louiscolumbus/2018/12/13/2018-roundup-of-internet-of-thingsforecasts-and-market-estimates/\#3dcf3a0f7d 83.

Copeland, B. J. (2020). Artificial intelligence. https://www.britannica.com/technology/artificialintelligence/Reasoning.

Coop. (2020). Who we are. https://www.coop.ch/en/company/about-us/who-we-are/retail.html.

Cramer, J., \& Krueger, A. B. (2016). Disruptive change in the taxi business: The case of Uber. American Economic Review, 106(5), 177-182.

Deloitte. (2018). Technology in the mid-market: Embracing disruption. https://www2.deloitte. $\mathrm{com} /$ content/dam/Deloitte/us/Documents/deloitte-private/us-private-tech-report-2018.pdf.

Dust, K. (1999). Culture, value and personality: Three flowering agents of creativity development process. American Journal of Applied Psychology. 2017, 5(1), 1-6. 
Elia, G., Margherita, A., \& Passiante, G. (2020). Digital entrepreneurship ecosystem: How digital technologies and collective intelligence are reshaping the entrepreneurial process. Technological Forecasting and Social Change, 150, 119791.

Ernst and Young Americas. (2018). How creativity can help the C-suite seize IoT opportunities. https://www.ey.com/en_us/digital/how-creativity-can-help-the-c-suite-seize-iot-opportunities.

Fade, L. (2020). Council post: How virtual reality is impacting enterprise training. Forbes. https:// www.forbes.com/sites/theyec/2020/03/10/how-virtual-reality-is-impacting-enterprise-training/ \#13a1c453704b.

Farshid, M., Paschen, J., Eriksson, T., \& Kietzmann, J. (2018). Go boldly!: Explore augmented reality (AR), virtual reality (VR), and mixed reality (MR) for business. Business Horizons, 61 (5), 657-663.

Fatemi, F. (2018). How AI will augment human creativity. https://www.forbes.com/sites/ falonfatemi/2018/08/17/how-ai-will-augment-human-creativity/\#48a6d66711b4.

Frey, C. B., \& Osborne, M. A. (2017). The future of employment: How susceptible are jobs to computerisation? Technological Forecasting and Social Change, 114, 254-280. https://doi. org/10.1016/j.techfore.2016.08.019.

Gabora, L. (2013). Psychology of Creativity. In E. G. Carayannis (Ed.), Encyclopedia of creativity, invention, innovation, and entrepreneurship (pp. 1515-1520).

Gardner, H., \& Weinstein, E. (2018). Creativity: The view from Big C and the introduction of tiny c. In R. Sternberg, J. Kaufman (Eds.), The nature of human creativity (pp. 94-109). New York, NY: Cambridge University Press.

Ghoshal, A. (2017). This AI-powered logo design service shows how much we need human designers. https://thenextweb.com/artificial-intelligence/2017/08/08/this-ai-powered-logodesign-service-shows-how-much-we-need-human-designers/.

Globenewswire. (2020). Global VR market is expected to reach usd 56.25 billion by 2025: Fior markets. https://www.globenewswire.com/news-release/2020/02/25/1989760/0/en/Global-VRMarket-is-Expected-to-Reach-USD-56-25-Billion-by-2025-Fior-Markets.html.

Gilson, L. L., \& Litchfield, R. C. (2017). Idea collections: A link between creativity and innovation. Innovation, 19(1), 80-85.

Goasduff, L. (2019). Top trends on the Gartner Hype cycle for artificial intelligence. https://www. gartner.com/smarterwithgartner/top-trends-on-the-gartner-hype-cycle-for-artificial-intelligence2019/.

Graessler, I., Taplick, P., \& Pottebaum, J. (2017). Enhancing innovation processes by disruptive technologies. SCIFI-IT, 2017, 19-26.

Graessler, I., \& Taplick, P. (2018). Virtual reality unterstützte Kreativitätstechnik: Vergleich mit klassischen Techniken. Krause, D., Paetzold, K. and Wartzack, S. (Hrsg.) Design for X Beiträge zum 29. DfX-Symposium, S. 215-226.

Hamdouna, M. (2018). Augmented reality in businesses: What will the future look like? https:// www.entrepreneur.com/article/324411.

Haynes, S. (2019). This robot artist just became the first to stage a solo exhibition. What does that say about creativity? https://time.com/5607191/robot-artist-ai-da-artificial-intelligence-creativity/.

HOK. (2020). About. https://www.hok.com/about/.

Howarth, D. (2018). Architectural renderings are "troublesome and problematic" says Es Devlin. https://www.dezeen.com/2018/05/10/architectural-renderings-troublesome-problematic-esdevlin-interview/.

$\mathrm{Hu}, \mathrm{L}$. (2015). Creativity in the Internet of things era. https://www.provokemedia.com/agencyplaybook/sponsored/article/creativity-in-the-internet-of-things-era.

Johnson, C. (2016). How digital media has changed creativity. https://www.deseret.com/2016/11/ 23/20600988/how-digital-media-has-changed-creativity\#corrina-harrington-3-of-eau-clairewis-plays-with-air-blowers-in-the-forces-at-play-exhibit-at-the-minnesota-childrens-museumin-st-paul-minn-on-tuesday-nov-22-2016.

Kamel, J. A. N., Martins, C. V., Pessanha, M. B., \& de Andrade, M. W. (2017). Creativity and innovation for corporate happiness management. Brazilian Journal of Science and Technology, 4(1), 1. 
Kapoor, P. (2019). How to boost employee creativity with technology, and why you should. https:// thriveglobal.com/stories/boosting-employee-creativity-with-technology/.

KPMG. (2018). The changing landscape of disruptive technologies. https://assets.kpmg/content/ dam/kpmg/pl/pdf/2018/06/pl-The-Changing-Landscape-of-Disruptive-Technologies-2018.pdf.

Kuratko, D. F., \& Morris, M. H. (2018). Corporate entrepreneurship: A critical challenge for educators and researchers. Entrepreneurship Education and Pedagogy, 1(1), 42-60.

Landry, L. (2017). The importance of creativity in business. https://www.northeastern.edu/ graduate/blog/creativity-importance-in-business/.

Lau, K. W., \& Lee, P. Y. (2012). The use of virtual reality for creating unusual environmental stimulation to motivate students to explore creative ideas. Interactive Learning Environments, 23(1), 3-18.

Leftronic. (2019) Artificial intelligence statistics. https://leftronic.com/artificial-intelligencestatistics/.

Liu, S. (2020). Internet of things. https://www.statista.com/topics/2637/internet-of-things/.

Long, D. (2019). NCSEA awards firms for structural engineering excellence. http://www.ncsea. com/downloads/files//2019\%20Summit/Press\%20Releases/2019\%20NCSEA\%20Awards\%20 Press\%20Release.pdf.

Loper, N. (2018). Brandmark. https://www.virtualassistantassistant.com/brandmark.

Loveless, A. (2002). Literature review in creativity, new technologies and learning. https://telearn. archives-ouvertes.fr/hal-00190439.

Magalhães, R. (2019). Come together: Using AI to enhance creativity. https://unbabel.com/blog/ artificial-intelligence-creativity/.

Marr, B. (2018). The key definitions of artificial intelligence (AI) that explain its importance. https://www.forbes.com/sites/bernardmarr/2018/02/14/the-key-definitions-of-artificialintelligence-ai-that-explain-its-importance/\#203124ae4f5d.

Marr, B. (2020). Can machines and artificial intelligence be creative? https://www.forbes.com/sites/ bernardmarr/2020/02/28/can-machines-and-artificial-intelligence-be-creative/\#48ab79374580.

Mehta, R., \& Dahl, D. W. (2019). Creativity: Past, present, and future. Consumer Psychology Review, 2(1), 30-49.

Milenkovic, J. (2019). Astounding artificial intelligence statistics for 2020. https://kommandotech. $\mathrm{com} /$ statistics/artificial-intelligence-statistics/.

Owler. (2020). Scandit's competitors, revenue, number of employees, funding and acquisitions. https://www.owler.com/company/scandit.

Pedersen, J. S., Slavich, B., \& Khaire, M. (2019). Technology and creativity: Production, mediation and evaluation in the digital age. Technology and Creativity, 1-11.

Petrov, C. (2019). 35 virtual reality statistics that will rock the market in 2020. https://techjury.net/ stats-about/virtual-reality/\#gref.

Phaneuf, A. (2020). Top IoT business opportunities, benefits, and uses in 2020. https://www. businessinsider.com/iot-business-opportunities-models?international=true \& $r=U S \& I R=T$.

Rao, A. \& Verweij, G. (2017). Sizing the price. https://www.pwc.com/gx/en/issues/analytics/ assets/pwc-ai-analysis-sizing-the-prize-report.pdf.

Said-Metwaly, S., Van den Noortgate, W., \& Kyndt, E. (2017). Approaches to measuring creativity: A systematic literature review. https://content.sciendo.com/view/journals/ctra/4/2/ article-p238.xml?lang=en.

Sawers, P. (2018). GV leads $\$ 30$ million investment in Scandit to bring AR and computer vision to mobile barcode scanning. https://venturebeat.com/2018/07/26/gv-leads-30-million-investmentin-mobile-barcode-scanning-company-scandit/.

Scandit. (2019). Understanding the Internet of things. https://www.scandit.com/blog/understandingthe-internet-of-things/.

Scandit. (2020). About Scandit. https://www.scandit.com/company/.

Science Business. (2013). Scandit develops highly optimized glass-based scanning experience for Google glass applications. https://sciencebusiness.net/news/76367/Scandit-Develops-HighlyOptimized-Glass-Based-Scanning-Experience-for-Google-Glass-Applications. 
Sefton-Green, J. (2018). Is there such a thing as digital creativity? https://clalliance.org/blog/isthere-such-a-thing-as-digital-creativity/.

Smith, C. S. (2020). Computers already learn from us. But can they teach themselves? https://www. nytimes.com/2020/04/08/technology/ai-computers-learning-supervised-unsupervised.html.

Soltanifar, M. (2016). Corporate entrepreneurship and triple helix. In Multinational Management (pp. 275-299). Springer, Cham.

Stamford, C. (2019). Gartner survey shows 37 percent of organizations have implemented AI in some form. https://www.gartner.com/en/newsroom/press-releases/2019-01-21-gartner-surveyshows-37-percent-of-organizations-have.

Uzzi, B. (2019). When mind meets machine: How AI can boost your creativity. https://www. forbes.com/sites/brianuzzi/2019/06/26/when-mind-meets-machine-how-ai-can-boost-yourcreativity/\#4ddbb40c7629.

van Lopik, K., Sinclair, M., Sharpe, R., Conway, P. \& West, A. (2020). Developing augmented reality capabilities for industry 4.0 small enterprises: Lessons learnt from a content authoring case study. Computers in Industry, 117, 103208.

York, G. (2020). Help lightning strikes success by using Vonage Video API. https://www.vonage. com/resources/customers/help-lightening/.

Weber, J. (2019). Fascinating facts about the Internet of things. https://www.sagiss.com/small_ business_technology_blog/2019-edition-20-fascinating-facts-about-the-internet-of-things.

Whyte, C. (2019). AI created images of food just by reading the recipes. https://www.newscientist. com/article/2190259-ai-created-images-of-food-just-by-reading-the-recipes/\#ixzz6K6GK35So.

Open Access This chapter is licensed under the terms of the Creative Commons Attribution 4.0 International License (http://creativecommons.org/licenses/by/4.0/), which permits use, sharing, adaptation, distribution and reproduction in any medium or format, as long as you give appropriate credit to the original author(s) and the source, provide a link to the Creative Commons license and indicate if changes were made.

The images or other third party material in this chapter are included in the chapter's Creative Commons license, unless indicated otherwise in a credit line to the material. If material is not included in the chapter's Creative Commons license and your intended use is not permitted by statutory regulation or exceeds the permitted use, you will need to obtain permission directly from the copyright holder.

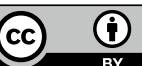

